\title{
Evaluation of rapid diagnostic test for influenza
}

\section{Tiziano Allice, Valeria Ghisetti}

\author{
S.C. Microbiologia, Ospedale Molinette, \\ Azienda Ospedaliera San Giovanni Battista di Torino, Italy
}

Key Words: Influenza virus, Rapid diagnostic test

Test rapidi per l'identificazione dei virus dell'influenza

\section{SUMMARY}

In high risk patients such as in eldery, newborns and immunosuppressed subjects, a timely diagnosis of influenza is required for the most appropriate antiviral strategy in order to avoid severe secondary respiratory complications and viral spreading. Influenza is preventable by vaccination and chemoprophylaxis and is treatable by specific antiviral indications.

The need for a timely diagnosis has led to the introduction of numerous rapid diagnostic tests. These are mostly antigen detection test giving results within 30 minutes, a clinically relevant time-frame to complement with the use of antiviral medications or chemoprophylaxis strategy.

When evaluating performances of rapid test for influenza viruses, it is important to consider the type and quality of specimen to be tested, as well as sensitivity and specificity of the assays. Nasal/nasopharyngeal swabs are the most frequently submitted specimens, but nasal/nasopharingeal aspirates and washs can improve the diagnostic sensitivity of the test. Only some rapid assays can be successful used with broncoalveolar washings.

In this review, we evaluated the sensitivity, specificity, reproducibility and feasibility of the most currently licensed rapid tests for influenza virus $A$ and $B$. A flow-chart for the laboratory diagnosis of influenza with rapid test in combination with confirmatory test is proposed.

\section{Received May 16, 2007}

\section{INTRODUZIONE}

L'influenza è una infezione importante per le complicanze che interessano bambini piccoli, lattanti, anziani e ospiti immunocompromessi, e che sono per lo più dovute a sovrainfezione batterica (Staphylococcus aureus, Haemophilus influenzae e Streptococcus pneumoniae) con possibili quadri di polmonite, bronchite, bronco-polmonite, tracheiti e lariginti con laringospasmo, Toxic Shock Syndrome e Sidrome di Reye.

Essendo disponibili antivirali efficaci contro i virus dell'influenza, è importante per i pazienti a rischio, sia una diagnosi rapida per l'identificazione dei virus influenzali, perché l'intervento terapeutico risulta efficace se effettuato entro le 48 ore dall'insorgenza dei primi sintomi, sia la differenziazione tra infezioni simili dovute a virus diversi (es. Rinovirus, virus respiratorio sinciziale, Adenovirus, virus parainfluenzali).

L'identificazione rapida dei virus influenzali ha inoltre un ruolo importante in ambito nosocomiale per la necessità di attuare misure di conteni-
Accepted December 17, 2007

mento della diffusione dell'infezione tra i pazienti o tra il personale sanitario ed i pazienti, in unità ad alto rischio come quelle ematologiche, oncologiche e di trapianto di cellule staminali emopoietiche. Infatti, l'infezione si trasmette da persona a persona attraverso "droplets", goccioline di liquido proveniente dalle basse e/o alte vie respiratorie, e i virus hanno la capacità di sopravvivere per un certo periodo di tempo in queste secrezioni, a livello delle superfici dove si depositano, penetrando nell'organismo attraverso le mucose della bocca, degli occhi e del naso. Il soggetto infetto può trasmettere l'infezione fino a sette giorni dopo la comparsa dei primi sintomi (che si manifestano entro circa quattro giorni dall'infezione); il periodo d'incubazione è breve (24-48 ore).

Le tecniche di diagnosi rapida sono pertanto un approccio fondamentale dal punto di vista clinico per l'identificazione dei virus e dal punto di vista epidemiologico per il controllo della trasmissione da contatto e attraverso droplet, ma rimandano a tecniche più complesse per l'isolamento e la

\section{Corresponding author: Tiziano Allice}

Laboratorio di Microbiologia, Ospedale Molinette,

Azienda Ospedaliera San Giovanni Battista di Torino - C.so Bramante 88 - 10126 Torino, Italy

Tel: 0 I I 633 437I - Fax:0II 633 5194 - E-mail: tizall@yahoo.it 
caratterizzazione del ceppo a scopo epidemiologico. Infatti, è solo l'isolamento in coltura che consente il mantenimento del ceppo virale e la sua caratterizzazione mediante tecniche molecolari basate sull'amplificazione dell'acido nucleico (reazione di polymerase chain reaction) e il sequenziamento degli acidi nucleici virali che ne permettono la tipizzazione finale indispensabile per una corretta sorveglianza epidemiologica dei ceppi circolanti ai fini della definizione delle specifiche del vaccino. La Tabella 1 riassume i principali metodi per l'identificazione dei virus influenzali e il loro campo di applicazione.

Scopo di questa rassegna è una valutazione dei metodi rapidi di identificazione dei virus influenzali direttamente dai materiali biologici, disponibili in commercio. Per ciascun test rapido, è stato effettuato un esame di tutti i più recenti lavori disponibili in letteratura e sono state considerate e confrontate le seguenti caratteristiche: il principio di funzionamento, il tipo di antigene virale identificato e i materiali biologici idonei, valutando in particolare l'adattabilità dei test ai materiali provenienti dalle bassa vie respiratorie, il loro possibile utilizzo al lavaggio bronco-alveolare nel caso di sospetta polmonite virale, la sensibilità e specificità rispetto alla coltura, ed infine il tempo di esecuzione di ciascuna metodica. Ove disponibile, è stato anche valutato il dato relativo alla capacità dei test di identificare varianti aviarie del virus dell'influenza A.

Le tecniche rapide per l'identificazione dei virus dell'influenza possono essere distinte in:

- metodi immunometrici (IMM) e immunocromatografici (ICM)

- metodi in immunofluorescenza (IFA). Le tecniche molecolari basate sull'amplificazione dell'acido nucleico virale (Polymerase Chain Reaction) possono rientrare tra i metodi rapidi, in quanto l'identificazione dei virus può avvenire entro un giorno dal prelievo, ma non sono incluse in questa rassegna per la loro complessità.
Tutti i metodi rapidi sono in grado di identificare i due principali tipi del virus dell'influenza e la maggior parte ne permette anche la differenziazione (A e B).

\section{Materiali dalle vie respiratorie}

Per identificare in modo corretto il virus dell'influenza è necessario che il prelievo del campione avvenga entro non più di quattro giorni dall'insorgenza dei sintomi influenzali e che sia trasportato in laboratorio nel più breve tempo possibile.

I virus influenzali possono essere identificati dai seguenti materiali:

- aspirati nasali, nasofaringei e tracheali

- lavaggi nasali, nasofaringei e tracheali

- tamponi nasali, faringei e nasofaringei

- escreato

- broncoaspirato

- lavaggi broncoalveolari (BAL)

Per i test rapidi, i lavaggi nasali e gli aspirati nasofaringei sono più idonei dei tamponi corrispondenti in quanto in grado di prelevare più materiale cellulare, requisito fondamentale per tali test.

Il trasporto condiziona in maniera determinante la maggiore o minore accuratezza di un test rapido: gli escreati o gli aspirati nasali devono essere raccolti e trasportati in contenitori sterili mentre i tamponi richiedono terreni di trasporto specifici per i virus (12). Infine tutti i campioni devono essere processati in un periodo di tempo non superiore alle 24 ore dopo le quali il successo del test nel recuperare i virus è molto più basso, e durante questo tempo conservati ad una temperatura compresa tra i 2 e $8^{\circ} \mathrm{C}(40)$.

\section{Metodi immunometrici (IMM) e immunocro- matografici (IMC)}

Questi metodi si basano principalmente sul riconoscimento degli antigeni influenzali mediante anticorpi diretti contro antigeni virali specifici, coniugati con enzimi che reagiscono con substra-

Tabella I. Metodi per l'identificazione dei virus influenzali

\begin{tabular}{|c|c|c|}
\hline METODI & SCOPO DIAGNOSTICO & APPLICAZIONE \\
\hline$\overline{\mathrm{IMC}^{\prime} / \mathrm{IM} \mathrm{M}^{2}}$ & $\begin{array}{l}\text { Diagnosi rapida } \\
\text { Diagnosi differenziale tra virus respiratori } \\
\text { Identificazione virus } A \text { e virus } B\end{array}$ & Clinica \\
\hline$\overline{\mathrm{IFA}^{3}}$ & $\begin{array}{l}\text { Diagnosi rapida } \\
\text { Diagnosi differenziale tra virus respiratori } \\
\text { Identificazione virus } A \text { e virus } B\end{array}$ & Clinica \\
\hline Coltura & $\begin{array}{l}\text { Identificazione, caratterizzazione e } \\
\text { mantenimento del ceppo }\end{array}$ & $\begin{array}{l}\text { Sorveglianza epidemiologia, } \\
\text { tipizzazione (tipo, sottotipo virale) } \\
\text { e sviluppo vaccino }\end{array}$ \\
\hline Test molecolari & $\begin{array}{l}\text { Diagnosi rapida } \\
\text { Diagnosi differenziale tra virus respiratori } \\
\text { Identificazione e tipizzazione a scopo } \\
\text { epidemiologico mediante sequenziamento virale }\end{array}$ & $\begin{array}{l}\text { Clinica, } \\
\text { sorveglianza epidemiologica e } \\
\text { tipizzazione (tipo, sottotipo virale) }\end{array}$ \\
\hline
\end{tabular}


ti cromogeni che sviluppano una reazione colorimetrica visibile. Un solo test fa eccezione poiché basato sulla capacità di rilevare l'attività enzimatica delle proteine simil-neuraminidasi presenti unicamente nei virus dell'influenza A e B.

Tutti sono dei test estremamente rapidi (10-30 minuti), facilmente eseguibili (numero di passaggi compreso tra 2 e 8) e non richiedono strumentazione.

Non tutti i campioni biologici danno risultati equivalenti; gli escreati e gli aspirati o lavaggi nasali sono considerati tra i materiali di partenza migliori mentre i tamponi nasali e nasofaringei risultano meno sensibili $(8,18,20,24,28)$.

La tipologia di pazienti determina un differente risultato nei test rapidi; risultati migliori si ottengono quando si analizzano campioni provenienti da bambini in cui la percentuale di positività è maggiore rispetto agli adulti per l'alta carica virale $(23,26)$.

Tutti i test rapidi in commercio sono in grado di identificare un'ampia popolazione di virus influenzali umani sia di tipo A sia di tipo B e presentano le seguenti caratteristiche:

- danno il risultato in meno di 30 minuti;

- non sono richieste strumentazioni particolari e possono essere utilizzati in ambulatori e direttamente al letto dei malati;

- sono dei saggi immunologici e si basano sul riconoscimento degli antigeni virali con specifici anticorpi;

- tutti identificano il virus dell'influenza A, quasi tutti anche il virus dell'influenza B e solo alcuni sono in grado di distinguere i due tipi influenzali (A e B);

- nessuno è in grado d' identificare i virus dell'influenza di tipo C;

- la sensibilità dipende dalla carica virale e quindi dal titolo antigenico presente nel campione e può non corrispondere all'esito della coltura cellulare eseguita sullo stesso campione;

- l'ottenimento di un risultato negativo non esclude la presenza di infezione da virus dell’influenza A e B. Per una diagnosi precisa è necessario associare elementi clinici ed eventualmente confermare il risultato con test di laboratorio più "sicuri";

- solo alcuni sono adatti ad identificare i virus influenzali a partire da lavaggi broncoalveolari.

Questi test possono essere presenti in versioni capaci di riconoscere i virus influenzali ma non distinguere il tipo A da quello B, ed in versioni in grado di identificare e distinguere il virus dell'influenza A e B. Il virus dell'influenza A è quello isolato con maggior specificità rispetto al virus dell'influenza B $(7,27)$ ma nessun test è in grado di distinguerne i sottotipi.

Nella presente rassegna sono stati analizzati undici differenti test rapidi (Directigen FluA, Directigen Flu $A+B$, Directigen EZ Flu $A+B$, ZstatFlu test, FLU OIA, Quick vue Influenza test, Quick vue Influenza $A+B$ test, NOW FluA and NOW FluB, NOW Influenza $A+B$, Espline Influenza A\&B-N e ImmunoCard STAT FluA and $B$ Plus) le cui caratteristiche sono riassunte nelle Tabelle 2a e 2b.

Tabella 2a. Caratteristiche dei principali test rapidi analizzati per la diagnosi dei virus dell'influenza

\begin{tabular}{|c|c|c|c|c|}
\hline Test rapido & $\begin{array}{c}\text { virus } \\
\text { influenzali } \\
\text { identificati }\end{array}$ & $\begin{array}{c}\text { Tempo di } \\
\text { esecuzione }(\mathrm{min})\end{array}$ & materiali di partenza & marchio $\mathrm{CE}^{\mathrm{a}}$ \\
\hline Directigen Flu A & A & 15 & $\begin{array}{l}\text { lavaggi, tamponi e aspirati } \\
\text { nasofaringei; tamponi faringei, } \\
\text { lavaggi broncoaveolari }\end{array}$ & Sì \\
\hline Directigen Flu A + FluB & $A \& B$ & 15 & $\begin{array}{l}\text { lavaggi, aspirato e tamponi } \\
\text { nasofaringei, tamponi faringei e } \\
\text { lavaggi broncoalveolari }\end{array}$ & Sì \\
\hline Directigen EZ Flu A + FluB & $A \& B$ & 15 & $\begin{array}{l}\text { lavaggi e aspirati nasofaringei e } \\
\text { tamponi faringei }\end{array}$ & Sì \\
\hline ZstatFlu & $A \circ B$ & $20-25$ & tamponi faringei e nasofaringei & No \\
\hline Flu OIA & $A \circ B$ & $15-20$ & \begin{tabular}{|l|} 
tamponi faringei e nasofaringei, \\
aspirati nasali e escreati, lavaggi \\
nasofaringei, lavaggi \\
broncoalveolari
\end{tabular} & Sì \\
\hline Quick vue Influenza test & $A \circ B$ & 10 & $\begin{array}{l}\text { tamponi nasali, lavaggi nasali e } \\
\text { aspirati nasali }\end{array}$ & No \\
\hline Quick vue Influenza A+B & $A \& B$ & 10 & $\begin{array}{l}\text { tamponi nasali, lavaggi nasali e } \\
\text { aspirati nasali }\end{array}$ & No \\
\hline NOW FluA and NOW FluB & $A \& B$ & 15 & $\begin{array}{l}\text { tamponi nasali e nasofaringei, } \\
\text { lavaggi e aspirati nasali, lavaggi } \\
\text { broncoalveolari }\end{array}$ & Sì \\
\hline NOW Influenza A \& B & $A \& B$ & 15 & $\begin{array}{l}\text { tamponi nasali e nasofaringei , } \\
\text { lavaggi e aspirati nasali }\end{array}$ & Sì \\
\hline $\begin{array}{l}\text { ImmunoCard STAT! Flu A } \\
\text { and B Plus test }\end{array}$ & $A \& B$ & $15-20$ & \begin{tabular}{|l} 
lavaggi nasali, tamponi e aspirati \\
nasofaringei, tamponi nasali
\end{tabular} & Sì \\
\hline Espline Influenza A\&B & $A \& B$ & 15 & $\begin{array}{l}\text { tamponi nasali e faringei, } \\
\text { aspirati nasali e faringei }\end{array}$ & No \\
\hline
\end{tabular}


Tabella 2b. Sensibilità e specificità dei principali test rapidi analizzati per la diagnosi dei virus dellinfluenza

\begin{tabular}{|c|c|c|c|c|}
\hline Test rapido & $\begin{array}{l}\% \text { Sensibilità media e } \\
\text { intervalli di confidenza } \\
\text { (tipo virale) }\end{array}$ & $\begin{array}{c}\% \text { Specificità media e } \\
\text { intervalli di confidenza } \\
\text { (tipo virale) }\end{array}$ & $\begin{array}{c}\text { sensibilità per } \\
\text { BAL }\end{array}$ & $\begin{array}{c}\mathrm{N}^{\circ} \text { lavori } \\
\text { valutati }\end{array}$ \\
\hline Directigen Flu A & $80,9 \pm 17,8(\mathrm{~A})$ & $93,7 \pm 7,3(\mathrm{~A})$ & nd & 6 \\
\hline Directigen Flu A + FluB & $\begin{array}{l}66,2 \pm 11,2(A) \\
54,2 \pm 14,5(B)\end{array}$ & $\begin{array}{l}98,9 \pm 1,4(\mathrm{~A}) \\
99,2 \pm 1,5(\mathrm{~B})\end{array}$ & $67 \%{ }^{\mathrm{b}}$ & 8 \\
\hline $\begin{array}{l}\text { Directigen EZ Flu A + } \\
\text { FluB }\end{array}$ & $\begin{array}{l}55,0 \pm 27,4 \text { (A) } \\
31,5 \pm 2,1 \text { (B) }\end{array}$ & $\begin{array}{l}98,0 \pm 2,0 \text { (A) } \\
99,0 \pm 2,0 \text { (B) }\end{array}$ & $0 \%^{\mathrm{b}}$ & 2 \\
\hline ZstatFlu & $81,1 \pm 5,5(A-B)$ & $79,3 \pm 11,1(\mathrm{~A}-\mathrm{B})$ & nd & 4 \\
\hline Flu OIA & $68,0 \pm 14,8(\mathrm{~A}-\mathrm{B})$ & $89,9 \pm 5,5(A-B)$ & $100 \%^{\mathrm{c}}$ & 8 \\
\hline Quick vue Influenza test & $80,0 \pm 8,5(A-B)$ & $90,3 \pm 4,1$ (A-B) & nd & 11 \\
\hline $\begin{array}{l}\text { Quick vue Influenza } \\
A+B\end{array}$ & $\begin{array}{l}67,0(\mathrm{~A}) \S \\
30,0(\mathrm{~B}) \S \\
\end{array}$ & $\begin{array}{l}100 \%(A) \S \\
100 \%(B) \S \\
\end{array}$ & nd & 1 \\
\hline $\begin{array}{l}\text { NOW FluA and NOW } \\
\text { FluB }\end{array}$ & $\begin{array}{l}64,9 \pm 9,6(A) \\
59,0 \pm 28,1(B) \\
\end{array}$ & $\begin{array}{l}96,2 \pm 2,0 \text { (A) } \\
98,3 \pm 3,3 \text { (B) }\end{array}$ & $100 \%{ }^{b}$ & 5 \\
\hline NOW Influenza A \& B & $\begin{array}{c}65,5 \pm 14,7(\mathrm{~A}) \\
31,5 \pm 2,9(\mathrm{~B})\end{array}$ & $\begin{array}{c}99 \%(\mathrm{~A}) \S \\
100 \%(\mathrm{~B}) \S \\
\end{array}$ & nd & 2 \\
\hline $\begin{array}{l}\text { ImmunoCard STAT! Flu } \\
\text { A and B Plus test }\end{array}$ & $\begin{array}{l}80,0(A) \S \\
47,0(B) \S \\
\end{array}$ & $\begin{array}{l}98 \%(A) \S \\
100 \%(B) \S\end{array}$ & nd & 1 \\
\hline Espline Influenza A\&B & $\begin{array}{c}95,5 \pm 7,0(\mathrm{~A}) \\
87,6+16,5(\mathrm{~B}) \\
\end{array}$ & $\begin{array}{l}99,4 \pm 1,2 \text { (A) } \\
99,2 \pm 1,6 \text { (B) }\end{array}$ & nd & 4 \\
\hline
\end{tabular}

\section{Directigen FluA Test (Becton Dickinson) Principio del test:}

è un test immunocromatografico su membrana per il virus dell'influenza A. Il virus viene estratto dal campione con una soluzione composta da agenti mucolitici e detergenti, legato in maniera aspecifica alla superficie della membrana del dispositivo del test, quindi identificato da anticorpi monoclonali per la nucleoproteina virale (nucleoproteina del virus influenza A) ed infine rilevato da una reazione colorimetrica. Il kit contiene un controllo interno di reazione, un controllo positivo per i virus dell'influenza A ed uno negativo.

\section{Materiale di partenza:}

lavaggi, tamponi e aspirati nasali e nasofaringei e lavaggi broncoalveolari.

\section{Sensibilità e specificità:}

la sensibilità varia dal 75 al 100\% mentre la specificità è compresa tra $84-100 \%(10,22,36,42)$.

\section{Tempo di esecuzione del test:}

meno di 15 minuti.

\section{Directigen Flu A + B (Becton Dickinson) \\ Principio del test:}

è analogo al precedente ma in grado di differenziare i virus dell'influenza A da quelli di tipo B. Il kit è dotato di un controllo positivo per i virus dell'influenza A e B e negativo e di un controllo interno di reazione.

\section{Materiale di partenza:}

lavaggi, tamponi e aspirati nasali e nasofaringei, tamponi faringei e lavaggi broncoalveolari.

\section{Sensibilità e specificità:}

i molti lavori (2, 6, 7, 11, 13, 21, 33, 35, 39, 43) che analizzano il test rapido Directigen Flu $A+B$ riportano sensibilità differenti: per il virus dell'influenza A valori compresi tra $43 \%$ e $96 \%$, mentre per il virus dell'influenza B, valori tra 29 e $87.5 \%$. I risultati di specificità del test, sono invece decisamente migliori: tra 94 e $100 \%$ per entrambi i virus influenzali $(6,7,11,13,21,33,35,39,43)$. Se si considera il tipo di pazienti analizzato, il test risulta essere più sensibile per i campioni provenienti dai bambini rispetto ai campioni prelevati da soggetti adulti $(2,13,21,33,35)$. Ruest et al (35) riportano una sensibilità del test pari a 95\% per campioni provenienti da bambini ( $<5$ anni), $86 \%$ per campioni provenienti da pazienti ospedalizzati e $83 \%$ per campioni provenienti da persone adulte. Inoltre il test presenta una buona sensibilità se si utilizzano i lavaggi broncoalveolari come campioni di partenza $(67 \%$, 43). Il test identifica varianti aviarie del virus dell'influenza A.

\section{Tempo di esecuzione del test:}

circa 15 minuti.

\section{Directigen EZ Flu A + B (Becton Dickinson) Principio del test:}

analogo ai precedenti e permette la rilevazione differenziale dei virus dell'influenza A e B. A differenza dei test Directigen FluA e Directigen Flu $A+B$, i virus dell'influenza A e B vengono identificati grazie alla visualizzazione colorimetrica del complesso antigene virale-anticorpo coniugato che, migrando su una membrana, si lega ad anticorpi anti-complesso immune. Il test consente di distinguere gli antigeni dei virus influenzali A da quelli B a partire da un solo campione trattato, usando un unico dispositivo. Il kit è dotato di un controllo positivo per i virus dell'in- 
fluenza A e B, un controllo negativo e un controllo interno di reazione.

\section{Materiale di partenza:}

i campioni adatti includono lavaggi e aspirati nasofaringei e tamponi faringei.

\section{Sensibilità e specificità:}

la sensibilità varia dal 41 al 69\% per il virus dell'influenza A e dal 30 al 33\% per il virus dell'influenza $\mathrm{B}$, mentre la specificità risulta migliore (97-100\% e $98-100 \%$, rispettivamente) $(19,43)$. Il test sembra essere molto più sensibile quando si parte da materiali respiratori quali lavaggi nasali, un po' meno se si utilizzano tamponi nasofaringei, e non adatto per i lavaggi broncoalveolari. Inoltre il test identifica varianti aviarie del virus dell'influenza A.

Tempo di esecuzione del test: circa 15 minuti.

\section{ZstatFlu test (ZymeTx, Inc.) Principio del test:}

reazione enzimatica delle neuraminidasi presenti sulla superficie dei virus dell'influenza A e B nei confronti del substrato costituito dall'acido Nneuraminico (Neu5Ac) a cui è legata una molecola di cromogeno; le neuraminidasi tagliano la molecola di cromogeno dando origine ad un prodotto di reazione colorato, indice della positività del test per la presenza dei virus dell'influenza A o B. I campioni sono incubati a $41^{\circ} \mathrm{C}$ in una miscela di reazione e poi trasferiti in un particolare supporto di lettura. I campioni positivi vengono identificati dal colore blu mentre quelli negativi, in cui non è avvenuta alcuna precipitazione, non presentano colorazione visibile. Un controllo interno permette di verificare la validità del test.

\section{Materiale di partenza:}

tamponi faringei e nasofaringei. Non sono riportati risultati per campioni provenienti da lavaggi broncoalveolari.

\section{Sensibilità e specificità:}

la sensibilità del test osservata in differenti lavori varia dal 70,1 al 98\% mentre la specificità dal 65 al 92\% (14, 27, 32, 34). Tale test risulta essere più sensibile rispetto ai test FLU OIA, e Quick Vue (14) ma molto simile al test Directigen FluA. Inoltre la sensibilità dipende dal tempo di incubazione dei campioni: Rawlinson e colleghi, (32) riportano valori di 65,77 e $98 \%$ per differenti tempi d'incubazione (20, 60 e 90 minuti, rispettivamente).

Tempo di esecuzione del test:

i risultati si ottengono in circa 20-25 minuti.

\section{FLU OIA (Biostar Inc.)}

\section{Principio del test:}

il test rapido FLU OIA per l’identificazione indif- ferenziata dei virus dell'influenza A e B è basato sulla reazione immunologica tra le nucleoproteine dei virus influenzali A e B e specifici anticorpi.

La reazione avviene a livello di un particolare substrato di silicio a cui sono adesi anticorpi per la nucleoproteina virale e che, se illuminato da una luce bianca, assume una colorazione dorata.

Al complesso antigene-anticorpo viene aggiunta una particolare pellicola che determina un cambiamento di colorazione del substrato.

Un campione risulta positivo quando il substrato siliceo su cui è fatto aderire e reagire assume una colorazione porpora. Il test è dotato di un controllo interno per la validazione della reazione.

\section{Materiale di partenza:}

tamponi faringei e nasofaringei, aspirati nasali ed escreati, lavaggi nasofaringei e lavaggi broncoalveolari.

\section{Sensibilità e specificità:}

la sensibilità osservata varia dal 40 al 100\%, dipende dal materiale di partenza utilizzato $(4,17$, $18,34,35,37,41)$ ed è maggiore per i tamponi nasofaringei $(17,41)$. Il test presenta una ottima sensibilità quando vengono utilizzati i lavaggi broncoalveolari come campioni di partenza (100\%, 18). La specificità varia dal 75.5 al 97\% ed è stato dimostrato che questo test è in grado d' identificare anche una varietà di virus influenzali aviari (41).

\section{Tempo di esecuzione del test:}

circa 20 minuti.

\section{Quick vue Influenza test (Quidel) \\ Principio del test:}

anticorpi monoclonali adesi a strip riconoscono le nucleoproteine dei virus influenzali. Non è un test in grado di differenziare tra influenza A e influenza B. Se il campione estratto contiene virus dell'influenza A o B, sulla striscia del test apparirà una linea rosa-rossa ed una linea azzurra di controllo ad indicare un risultato positivo.

\section{Materiale di partenza:}

tamponi nasali, lavaggi nasali e aspirati nasali. Al momento, non sono riportati risultati per campioni provenienti da lavaggi broncoalveolari.

\section{Sensibilità e specificità:}

la sensibilità del test Quick vue riportata in molti lavori $(1,3,16,20,29,31,34,35,38,44)$ risulta variare tra 69 e $99 \%$ mentre la specificità tra 76 e $99 \%$. Recenti lavori $(1,29,30,38)$ riportano valori molto buoni di sensibilità (rispettivamente 69$85 \%, 82 \%$ e $77 \%$ ), in particolare se si considerano i campioni provenienti dai pazienti pediatrici. Agoritsas et al (1) analizzano una popolazione di 122 bambini e differenziano la sensibilità del test in base al tipo di campioni utilizzati: per i tamponi nasofaringei è stato ottenuto un valore di sensi- 
bilità pari a 85\%, 78\% per i tamponi nasali e 69\% e per i lavaggi nasofaringei.

Tempo di esecuzione del test:

molto rapido, circa 10 minuti.

\section{Quick vue Influenza A+B test (Quidel)}

Principio del test: evoluzione del test Quick vue Influenza test, utilizza lo stesso principio di identificazione ma permette di distinguere i virus dell'influenza A da quelli B nella medesima strip di reazione.

\section{Materiale di partenza:}

tamponi nasali, lavaggi nasali e aspirati nasali.

$\mathrm{Al}$ momento, non sono riportati risultati per campioni provenienti da lavaggi broncoalveolari.

\section{Sensibilità e specificità:}

la sensibilità, ottenuta dall'unico lavoro finora disponibile (19), è pari a 67\% per il virus dell'influenza A e $30 \%$ per quello dell'influenza B.

La specificità è del $100 \%$ sia per il virus di tipo A sia per quello di tipo B. Inoltre il test identifica varianti aviarie del virus dell'influenza A.

\section{Tempo di esecuzione del test:}

circa 10 minuti.

\section{NOW FluA and NOW FluB (Binax Inc) \\ Principio del test:}

test immunocromatografico su membrana, che utilizza due distinti supporti specifici per i virus influenzali A e B. Il materiale respiratorio viene inizialmente lisato e addizionato alle membrane (una per l'identificazione dell' influenza A e l'altra per l'influenza B) dove i virus dell'influenza si legano ad anticorpi monoclonali ad elevata sensibilità che riconoscono gli antigeni nucleoproteici A e B. Gli immunocomplessi vengono immobilizzati su strisce costituite da un supporto membranoso e combinati con ulteriori reagenti per dare una reazione colorimetrica. Il kit è dotato di un controllo positivo per i virus dell'influenza A e B e negativo e di un controllo interno di reazione.

\section{Materiali di partenza:}

tamponi nasali e nasofaringei, lavaggi o aspirati nasali e lavaggi broncoalveolari.

\section{Sensibilità e specificità:}

alcuni lavori $(5,9,21,39,43)$, riportano valori di sensibilità che vanno dal 52 al $79 \%$ per il virus dell'influenza A e dal 33 al 100\% per il virus dell'influenza B. La sensibilità aumenta se si considerano i campioni provenienti da bambini (9, 21, 43) ed in particolare per l'identificazione dei virus dell'influenza A. I valori di sensibilità nei bambini per il virus influenzale A ottenuti negli studi di Cruz et al (9), Landry et al (21), e Weinberg e Walker (43) sono rispettivamente di 70.3\%, 69\% e $75 \%$. La sensibilità del test è migliore quando, come materiali respiratori di partenza, vengono utilizzati tamponi nasofaringei (100\%, 39 e 43) e lavaggi broncoalveolari $(100 \%$, 43). Tutti i lavori riportano una buona specificità per entrambi i virus influenzali (A: 93.3-99\% e B: 93.3-100\%).

\section{Tempo di esecuzione del test:}

15 minuti.

\section{NOW Influenza A+B (Binax Inc) \\ Principio del test:}

analogo al precedente ma in grado di differenziare i virus dell'influenza A da quelli B utilizzando un solo dispositivo.

\section{Materiale di partenza:}

tamponi nasali e nasofaringei, lavaggio o aspirati nasali. Al momento non sono riportati risultati per campioni provenienti da lavaggi broncoalveolari.

\section{Sensibilità e specificità:}

i due lavori che analizzano il test Binax Now Influenza $A+B(19,39)$ riportano valori di sensibilità sia per il virus dell'influenza A sia per il virus dell'influenza B simili a quelli ottenuti con il test NOW FluA and NOW FluB: 58 e 73\% per il virus dell'influenza A e 30 e $33 \%$ per il virus dell'influenza B. La specificità del test per entrambi i virus influenzali è molto alta in entrambi i lavori (99\% per il tipo A e 100\% per il tipo B). Inoltre il test identifica varianti aviarie del virus dell'influenza A.

\section{Tempo di esecuzione del test:}

circa 15 minuti.

\section{Espline Influenza A\&B-N (Fujirebo Inc) \\ Principio del test:}

saggio immunocromatografico per la diagnosi differenziale dei virus dell'influenza A e B. Il test è costituito da anticorpi marcati con fosfatasi alcalina specifica per le nucleoproteine dei virus A e B, anticorpi anti-fosfatasi-alcalina immobilizzati sulle linee di reazione della membrana di nitrocellulosa usata come supporto, e una molecola substrato (BCIP, 5-Bromo-4-chloro-3-indolyl-phosphate). Dopo lisi, il materiale respiratorio viene addizionato alla membrana di nitrocellulosa.

Gli immuno-complessi migrano fino alla corrispondente linea di reazione formando un immuno-complesso tipo "sandwich" con gli anticorpi anti-fosfatasi. Dopo l'aggiunta del substrato si ha sviluppo di colore, indice della positività del test.

\section{Materiali di partenza:}

tamponi faringei, nasali, aspirati nasali e nasofaringei. Al momento, non sono riportati risultati per lavaggi broncoalveolari.

\section{Sensibilità e specificità:}

tutti i lavori disponbili $(15,16,19,25,31)$, riportano una buona sensibilità del test per l'identificazione dei virus influenzali B (71-100\%) tranne un recentissimo lavoro (19) che riporta una sensibili- 
tà pari al 30\%. Molto buona risulta invece per tutti i lavori analizzati la sensibilità per i virus influenzali di tipo A (67-100\%); in due lavori (15 e 16), vengono riportate sensibilità per il virus dell'influenza A pari al $100 \%$. La sensibilità del test risulta altrettanto alta quando vengono considerano differenti materiali respiratori di partenza; Mitamura et al (25) analizzano 131 aspirati nasali, 95 lavaggi nasali, e 74 tamponi nasali ottenendo una sensibilità per il virus dell'influenza A pari a $95.4 \%, 96.8 \%$ e $85.1 \%$ rispettivamente, mentre per il virus dell'influenza B pari a $91.2 \%, 88.1 \%$ e $71.6 \%$. Anche la specificità per entrambi i virus influenzali, in tutti i lavori analizzati, risulta essere molto buona, dal 97.6 al $100 \%$ sia per il virus A che $\mathrm{B}(15,16,19,25,31)$.

Tempo di esecuzione del test:

i risultati si ottengono in circa 15 minuti.

\section{ImmunoCard STAT FluA and B Plus (Meridian Bioscience) \\ Principio del test:}

saggio immunocromatografico per la rilevazione differenziale dei virus dell'influenza A e B. Utilizza anticorpi monoclonali che riconoscono e si legano alle nucleoproteine dei virus influenzali di tipo A e B. La positività viene evidenziata dalla colorazione in rosa-rosso della specifica linea per l'influenza A o di quella per l'influenza B. Il kit è dotato di un controllo interno per la validazione della procedura.

\section{Materiale di partenza:}

il test è adatto per l'analisi di lavaggi nasali, tamponi e aspirati nasofaringei e nasali. Al momento, non sono riportati risultati per lavaggi broncoalveolari.

\section{Sensibilità e specificità:}

la sensibilità, ottenuta dall'unico lavoro finora disponibile (5), è pari a $80 \%$ per il virus dell'influenza A e 47\% per l'influenza B. La specificità ottenuta per il virus di tipo $\mathrm{A}$ è del $98 \%$ e del $100 \%$ per quello di tipo B.

\section{Tempo di esecuzione del test:}

15-20 minuti.

\section{Immunofluorescenza (IFA)}

Questa tecnica richiede più tempo dei test immunoenzimatici e immunocromatografici, perché il campione va preparato in modo adeguato ed è più complessa sia per la preparazione dei campioni, sia per la lettura dei risultati che richiede esperienza specifica. Trova spesso impiego nella conferma dei risultati positivi ai test rapidi immunometrici o in condizioni di urgenza relativa.

Esistono test in immunofluorescenza "rapidi”, allestiti con anticorpi specifici per i virus influenzali direttamente coniugati con fluorocromi (tempi di esecuzione a preparazione del campione di circa 20 minuti) e test meno "rapidi” indiretti, che prevedono l'uso di anticorpi primari specifici per i virus influenzali, non marcati, seguiti dall'incubazione con anticorpi secondari marcati, con tempi di esecuzione più lunghi. La fase critica è rappresentata dalla preparazione del campione, che prevede un adeguato numero di cellule provenienti dagli epiteli delle vie aeree e la relativa conservazione della morfologia. I test in immunofluerescenza sono di solito allestiti in formato multiplo per l'identificazione differenziale di altri virus respiratori, come il virus respiratorio sinciziale, gli adenovirus e i virus parainfluenzali 1 , 2 e 3 . I test "rapidi” di più recente introduzione sul mercato, usano la tecnica di immunofluorescenza diretta con anticorpi monoclonali fluoresceinati specifici per una nucleoproteina di $60 \mathrm{kDa}$ (Argene, Varilhes, F) caratteristica dei virus dell'influenza e comune a molti ceppi di virus ed espressi nel citoplasma delle cellule infettate. I materiali respiratori di partenza sono i più vari: tamponi nasali, nasofaringei e lavaggi broncoalveolari.

Per il corretto allestimento di preparati, il materiale deve essere centrifugato ad una velocità non superiore a $1000 \mathrm{rpm}$ per circa dieci minuti, per mantenere l'integrità delle cellule. I preparati possono essere allestiti per citocentrifugazione.

Il preparato viene quindi fissato preferibilmente in acetone freddo per 10 minuti e quindi viene incubato con l'anticorpo monoclonale specifico già fluorescinato. I tempi di incubazione $\left(a 7^{\circ} \mathrm{C}\right.$ ) variano da 15 a 30 minuti e, dopo alcuni lavaggi con tampone fosfato, si procede al montaggio del vetrino e alla lettura al microscopio. Esistono in commercio vetrini di controllo con preparati positivi per i diversi virus respiratori, che presentano pattern di fluorescenza differenti l'uno dall'altro, di regola forniti anche di rispettivi controlli negativi, che vanno allestiti contemporaneamente alla colorazione del campione in esame.

La sensibilità della tecnica di immunofluorescenza per i virus dell'influenza rispetto all'isolamento in coltura (tecnica di riferimento) va dal $70 \mathrm{al}$ $100 \%$, con una specificità tra l'80 e il $100 \%$. Il valore predittivo positivo va dall' 85 al $94 \%$ a seconda che ci si trovi in periodi di attività epidemica virale bassa o elevata e il valore predittivo negativo è compreso tra 96 e $100 \%$ (http://www.who.int/csr/disease/avian_influenz a / g u idelines/rapid_testing / en /, http://www.influenzareport.com).

\section{CONCLUSIONI}

L'identificazione rapida dei virus influenzali ha importanti conseguenze dal punto di vista clinico 
ed epidemiologico, quali la terapia dei soggetti ad alto rischio di complicanze infettive e la profilassi dei contatti. In generale, dall'analisi dei dati di letteratura, la sensibilità dei test rapidi rispetto alla coltura è del $75 \%$, mentre la specificità è più elevata (>97\%).

In particolare, è stata osservata una buona sensibilità dei test rapidi che identificano i virus dell'influenza A e B senza differenziarli e di quelli che permettono d'identificare unicamente il virus dell'influenza A. La non elevatissima sensibilità osservata è da imputare a differenti motivi:

a) il materiale di partenza: si tratta infatti di materiali complessi, ricchi di muco e detriti cellulari, il cui pretrattamento è minimo nei test rapidi e pertanto l'esposizione all'antigene virale non è sempre ottimale;

b) non si ha amplificazione in vivo (coltura) o in vitro (PCR) del target;

c) una scarsa disponibilità di dati di letteratura (per alcuni test è disponibile al momento un solo lavoro).

Di notevole interesse clinico ed epidemiologico è anche l'osservazione che la maggior parte di essi è in grado di identificare varianti aviarie del virus dell'influenza A.
I dati relativi alla sensibilità e specificità di questi test hanno importanza in rapporto al contesto epidemiologico in cui viene applicato il test rapido: durante la fase epidemica a seguito della sensibilità non ottimale possono verificarsi risultati falsamente negativi, mentre al di fuori di essa, invece, possono esserci risultati falsamente positivi che vanno confermati con test più sensibili e specifici come i metodi IFA. I test rapidi sono caratterizzati quindi, durante il periodo epidemico da un valore predittivo positivo elevato e basso valore predittivo negativo per la possibilità che si verifichino risultati falsi negativi, mentre nei periodi di bassa attività virale il valore predittivo positivo si abbassa e si alza quello predittivo negativo per la possibilità di risultati falsi positivi. Pertanto, per una diagnosi definitiva è opportuno affiancare i test rapidi a metodi convenzionali come l'isolamento in coltura e a metodi molecolari, attraverso l'invio a Centri di Riferimento, nell'ambito della rete di sorveglianza nazionale per l'Influenza.

La Figura I rappresenta una guida per l'utilizzo dei test diagnostici rapidi durante o al di fuori della fase epidemica, con in dettaglio le modalità di refertazione del risultato e gli eventuali test di conferma da associare.

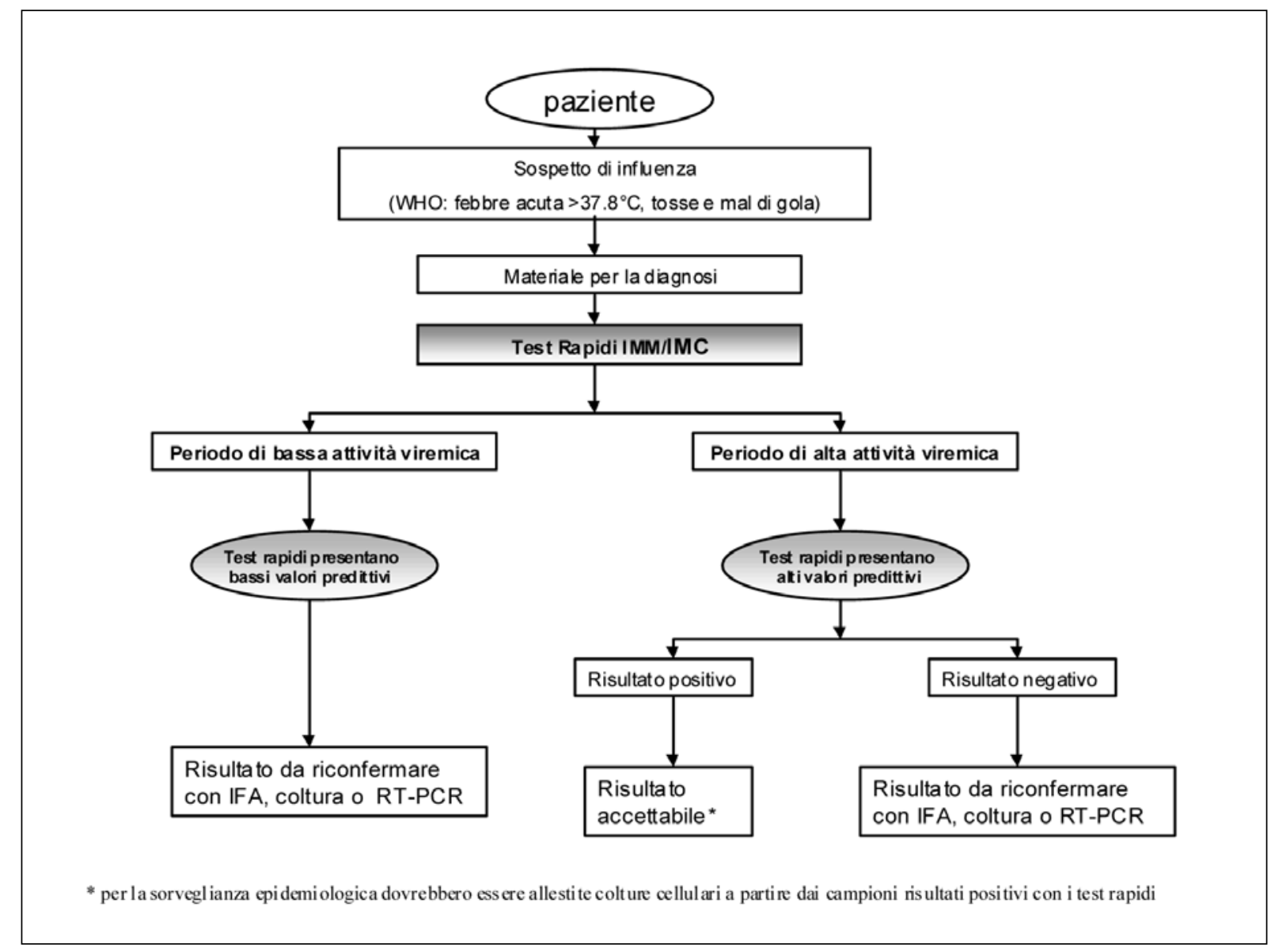

Figura I. Utilizzo dei test rapidi 


\section{BIBLIOGRAFIA}

1. Agoritsas K, Mack K, Bonsu BK, et al. Evaluation of the Quidel QuickVue test for detection of influenza A and $\mathrm{B}$ viruses in the pediatric emergency medicine setting by use of three specimen collection methods. $J$ Clin Microbiol 2006; 44: 2638-41

2. Alexander R, Hurt AC, Lamb D, et al. A comparison of a rapid test for influenza with laboratory-based diagnosis in a paediatric population. Commun Dis Intell 2005; 29: 272-6

3. Bellei N, Benfica D, Perosa AH, et al. Evaluation of a rapid test (QuickVue) compared with the shell vial assay for detection of influenza virus clearance after antiviral treatment. J Virol Methods 2003; 109: 85-8

4. Boivin G, Hardy I, Kress A. Evaluation of a rapid optical immunoassay for influenza viruses (FLU OIA test) in comparison with cell culture and reverse transcription-PCR. J Clin Microbiol 2001; 39: 730-2

5. Booth S, Baleriola C, Rawlinson WD. Comparison of two rapid influenza A/B test kits with reference methods showing high specificity and sensitivity for influenza A infection. J Med Virol 2006; 78: 619-22

6. Cazacu AC, Chung SE, Greer J, et al. Comparison of the directigen flu $\mathrm{A}+\mathrm{B}$ membrane enzyme immunoassay with viral culture for rapid detection of influenza $\mathrm{A}$ and $\mathrm{B}$ viruses in respiratory specimens. $J$ Clin Microbiol 2004; 42: 3707-10

7. Chan KH, Maildeis N, Pope W, et al. Evaluation of the Directigen FluA+B test for rapid diagnosis of influenza virus type A and B infections. J Clin Microbiol 2002; 40: 1675-80

8. Covalciuc KA, Webb KH, Carlson CA. Comparison of four clinical specimen types for detection of influenza A and B viruses by optical immunoassay (FLU OIA test)and cell culture methods. J Clin Microbiol 1999; 37: 3971-4

9. Cruz AT, Cazacu AC, McBride LJ, et al. Performance characteristics of a rapid immunochromatographic assay for detection of influenza virus in children during the 2003 to 2004 influenza season. Ann Emerg Med 2006; 47: 250-4

10. Dominguez EA, Taber LH, Couch RB. Comparison of rapid diagnostic techniques for respiratory syncytial and influenza A virus respiratory infections in young children. J Clin Microbiol 1993; 31: 2286-90

11. Dunn JJ, Gordon C, Kelley C, et al. Comparison of the Denka-Seiken INFLU A.B-Quick and BD Directigen Flu A+B kits with direct fluorescent-antibody staining and shell vial culture methods for rapid detection of influenza viruses. J Clin Microbiol 2003; 41: 2180-3

12. Gavin R, Thomson P. Review of Rapid Diagnostic Tests for Influenza. Clinical and Applied Immunology Reviews 2003; 4: 151-72

13. Grondahl B, Puppe W, Weigl J, et al. Comparison of the BD Directigen Flu A+B Kit and the Abbott TestPack RSV with a multiplex RT-PCR ELISA for rapid detection of influenza viruses and respiratory syncytial virus. Clin Microbiol Infect 2005; 11: 848-50.

14. Hamilton MS, Abel DM, Ballam YJ, et al. Clinical evaluation of the ZstatFlu-II test: a chemiluminescent rapid diagnostic test for influenza virus. J Clin Microbiol 2002; 40: 2331-4

15. Hara M, Takao S, Fukuda S, et al. Comparison of four rapid diagnostic kits using immunochromatography to detect influenza B viruses. Kansenshogaku Zasshi 2005; 79: 803-11

16. Hara M, Takao S, Fukuda S, et al. Comparison of three rapid diagnostic kits using immunochromatography for detection of influenza A virsuses.
Kansenshogaku Zasshi 2004; 78: 935-42

17. Herrmann B, Larsson C, Zweygberg BW. Simultaneous detection and typing of influenza viruses $\mathrm{A}$ and $\mathrm{B}$ by a nested reverse transcription-PCR: comparison to virus isolation and antigen detection by immunofluorescence and optical immunoassay (FLU OIA). J Clin Microbiol 2001; 39: 134-8

18. Hindiyeh M, Goulding C, Morgan H, et al. Evaluation of BioStar FLU OIA assay for rapid detection of influenza A and B viruses in respiratory specimens. $J$ Clin Virol 2000; 17: 119-26

19. Hurt AC, Alexander R, Hibbert J, et al. Performance of six influenza rapid tests in detecting human influenza in clinical specimens. J Clin Virol. 2007 doi: 10.1016/j.jcv.2007.03.002

20. Kawakami C, Shimizu H, Watanabe S, et al. Evaluation of immunochromatography method for rapid detection of influenza A and B viruses. Kansenshogaku Zasshi 2001; 75: 792-9

21. Landry ML, Cohen S, Ferguson D. Comparison of Binax NOW and Directigen for rapid detection of influenza A and B. J Clin Virol 2004; 31: 113-5

22. Leonardi GP, Leib H, Birkhead GS, et al. Comparison of rapid detection methods for influenza A and their value in health-care management of istitutionalized geriatric patients. J Clin Microbiol 1994; 32: 70-74

23. Long CE, Hall CB, Cunningham CK, et al. Influenza surveillance in community-dwelling elderly compared with children. Arch Fam Med 1997; 6: 459-65

24. McQuillin J, Madeley CR, Kendal AP. Monoclonal antibodies for the rapid diagnosis of influenza A and B virus infections by immunofluorescence. Lancet 1985; 2: 911-4

25. Mitamura K, Yamazaki M, Ichikawa M, et al. Evaluation of an immunochromatography test using enzyme immunoassay for rapid detection of influenza A and B viruses. Kansenshogaku Zasshi 2004; 78: 597-603

26. Murphy BR, Chalhub EG, Nusinoff SR, et al. Temperature sensitive mutants of influenza virus, III. Further characterization of the ts-1[E] influenza A recombinant (H3N2) virus in man. J Infect Dis 1973; 128: $479-87$

27. Noyola DE, Clark B, O’Donnell FT, et al. Comparison of a new neuraminidase detection assay with an enzyme immunoassay, immunofluorescence, and culture for rapid detection of influenza A and B viruses in nasal wash specimens. J Clin Microbiol 2000; 38: 1161-5

28. Noyola DE, Paredes AJ, Clark B, et al. Evaluation of a neuraminidase detection assay for the rapid detection of influenza A and B virus in children. Pediatr Develop Pathol 2000; 3: 162-7

29. Poehling KA, Zhu Y, Tang YW, et al. Accuracy and impact of a point-of-care rapid influenza test in young children with respiratory illnesses. Arch Pediatr Adolesc Med 2006; 160: 713-8

30. Pregliasco F, Puzelli S, Mensi C, et al. The Collaborative Group Influchild. Influenza virological surveillance in children: the use of the QuickVue rapid diagnostic test. J Med Virol 2004; 73: 269-73

31. Quach C, Newby D, Daoust G, et al. QuickVue influenza test for rapid detection of influenza A and B viruses in a pediatric population. Clin Diagn Lab Immunol 2002; 9: 925-6

32. Rawlinson WD, Waliuzzaman ZM, Fennell M, et al. New point of care test is highly specific but less sensitive for influenza virus A and B in children and adults. J Med Virol 2004; 74: 127-31

33. Reina J, Padilla E, Alonso F, et al. Evaluation of a new 
dot blot enzyme immunoassay (directigen flu $\mathrm{A}+\mathrm{B}$ ) for simultaneous and differential detection of influenza a and B virus antigens from respiratory samples. J Clin Microbiol 2002; 40: 3515-7

34. Rodriguez WJ, Schwartz RH, Thorne MM. Evaluation of diagnostic tests for influenza in a pediatric practice. Pediatr Infect Dis J 2002; 21: 193-6

35. Ruest A, Michaud S, Deslandes S, et al. Comparison of the Directigen flu A+B test, the QuickVue influenza test, and clinical case definition to viral culture and reverse transcription-PCR for rapid diagnosis of influenza virus infection. J Clin Microbiol 2003; 41: 3487-93

36. Ryan-Poirer KA, Katz JM, Webster RG, et al. Application of Directigen FLU-A for the detection of influenza A virus in human and nonhuman specimens. J Clin Microbiol 1992; 30: 1072-5

37. Schultze D, Thomas Y, Wunderli W. Evaluation of an optical immunoassay for the rapid detection of influenza A and B viral antigens. Eur J Clin Microbiol Infect Dis 2001; 20: 280-3

38. Simmerman JM, Chittaganpitch M, Erdman D, et al. Field performance and new uses of rapid influenza testing in Thailand. Int J Infect Dis 2007; 22: 166-71

39. Smit M, Beynon KA, Murdoch DR, et al. Comparison of the NOW Influenza A \& B, NOW Flu A, NOW Flu $\mathrm{B}$, and Directigen Flu $\mathrm{A}+\mathrm{B}$ assays, and immunofluo- rescence with viral culture for the detection of influenza A and B viruses. Diagn Microbiol Infect Dis 2007; 57: $67-70$

40. Steininger C, Kundi M, Aberle SW, et al. Effectiveness of reverse transcription-PCR, virus isolation, and enzyme-linked immunosorbent assay for diagnosis of influenza A virus infection in different age groups. J Clin Microbiol 2002; 40: 2051-6

41. Tucker SP, Cox C, Steaffens J. A flu optical immunoassay (ThermoBioStar's FLU OIA): a diagnostic tool for improved influenza management. Philos Trans R Soc Lond B Biol Sci 2001; 29 (356): 1915-24

42. Waner JL, Todd SJ, Shalaby, et al. Comparison of Directigen FLU-A with viral isolation and direct immunofluorescence for the rapid detection and identification of influenza A virus. J Clin Microbiol 1991; 29: 479-82

43. Weinberg A, Walker ML. Evaluation of three immunoassay kits for rapid detection of influenza virus A and B. Clin Diagn Lab Immunol 2005; 12: 367-70

44. Yamazaki M, Mitamura K, Kimura K, et al. Clinical evaluation of an immunochromatography test for rapid diagnosis of influenza. Kansenshogaku Zasshi 2001; 75: 1047-53 